\title{
A measurement of radiographers pandemic experiences \& perceptions survey (PEPS) during the coronavirus pandemic in Kuwait.
}

Muna AlMulla ( $\square$ muna.almulla@ku.edu.kw)

Kuwait university

Research Article

Keywords: Gulf (Kuwait); COVID-19; radiographers; risk; work

Posted Date: July 22nd, 2020

DOl: https://doi.org/10.21203/rs.3.rs-43360/v1

License: (1) This work is licensed under a Creative Commons Attribution 4.0 International License. Read Full License

Version of Record: A version of this preprint was published at Archives of Clinical and Biomedical Research on March 22nd, 2022. See the published version at https://doi.org/10.26502/acbr.50170247. 


\section{Abstract}

Aim

COVID-19 has present the working environment with terms such as volatility, uncertainty, complexity, and ambiguity, which are factors that has the potential to significantly result in the possible breakdown of the workforce as they experience more and more collapse of community, absence of fairness, and conflicting values. This study aimed to measure radiographers' experience during COVID-19 using pandemic experiences \& perceptions survey (PEPS) tool. The tool provides critical information on the extent of workflow disruption, the measure and availability of resources, risk perception, impact on working dynamics (workload, control, reward, community, fairness, and values) and management.

\section{Methods:}

An online survey was distributed from May 2020 to June 2020 to radiographers who work in Kuwait government, private hospitals, clinics, or newly authorized medical quarantine centers. The survey consists of 2 pages, 34 questions in total, with an additional added demographic page. In total, it takes 10 to 15 minutes to complete the survey. For reporting PEPS results, we used descriptive analysis for the demographic data, average scoring, and mean and standard deviation (SD) for the tool items.

\section{Results:}

The number of participants who attempted to answer the survey was 347; however, only 102 participants completed the survey. 48 (47.1\%) males and 54 (52.9\%) females, the questionnaire had a mean ( \pm SD) age of ( $35.7 \pm 8.2)$ years. $89 \%$ of participants have indicated that they have been in direct contact with COVID19. $57.8 \%$ have expressed that they have had the training, support, and equipment to provide minimal control over the virus. Furthermore, more than half of the participants $(68.7 \%)$ have expressed fear of the virus and that the virus presented a danger to them. With regards to the five PEPS tools, the mean \pm SD (table 1) were: Disruption $2.487( \pm 1.094)$, resources $2.580( \pm 1.196)$, risk perception $2.963( \pm 1.713)$, impact on work-life areas $3.810( \pm 0.992)$, and Leadership $3.795( \pm 0.965)$.

\section{Conclusion:}

The majority of radiographers explained fear and risk of working with COVID-19; however, they had a positive attitude toward their leadership and management. Most radiographers explained that regardless of their faith in management, additional education interventions and campaigns were required to improve their sense of safety and confidence. Working with an insensitive working environment of COVID-19, any organization will experience some burnout, depending on both the quality of the management system and how leaders react in real-time. This PEPS tool can help to contain future burnouts and conflicts.

\section{Introduction}


Since its surfacing in January, the COVID-19 pandemic has caused a lot of panic and chaos worldwide. Governments have had to lock down to reduce Coronavirus patient output and decrease the heavy load on healthcare systems. Hospitals, medical clinics, and different healthcare departments had to re-adjust their working dynamic to deal with this outbreak. According to the department of Occupational Safety and Health Administration (OSHA) healthcare workers are at high risk of infection because of their critical work controlling its outbreak (Occupational Safety and Health Administration (OSHA), 2020). They face mental stress, physical exhaustion, separation from families, stigma, and pain of losing patients and colleagues. Many of them have acquired the disease, and some have died (Chersich et al., 2020). According to the world health organization (WHO), and international Council of nurses (ICN) at least 90,000 healthcare workers worldwide believed to have been infected with COVID-19 (Catton, 2020), and more than 1000 people reportedly have been killed from dozens of countries, professions, and specialties. In Kuwait alone, reported COVID-19 healthcare worker infections are 105, with five confirmed deaths (Alnisif, 2020).

Most research for COVID-19 will have a general focus on healthcare professionals (Chersich et al., 2020, Zhang et al., 2020), this study will have a specificity of focusing on radiographers. There is a lack of data reporting on radiographers' wellbeing in Kuwait, specifically during this pandemic. Radiography plays a critical role in monitoring the spread of COVID-19. Alongside lab testing, one of the essential diagnostic tools used to identify the prevalence of COVID-19 is general radiography (X-Rays) and computed tomography (CT) imaging. Which make radiographers have a hands-on experience with COVID-19 patients (Stevens, 2020, Kooraki, Hosseiny and Gholamrezanezhad, 2020, Yurdaisik and Nurili, 2020, Flor, Dore and Sardanelli, 2020). Therefore their knowledge with COVID-19 is of great value to help prevent or spread infection (Sim et al., 2020). An assessment of employees' experiences can provide leaders with crucial guidance for managing the current situation, leading the organizational recovery afterward, and anticipating future challenges (Bhagavathula et al., 2020, Leiter, 2020).

Thus for this study, a Pandemic Experiences and Perceptions Survey (PEPS) is used to report on radiographer experience. The PEPS is a powerful tool to measure employees' experience during a pandemic providing critical information on the extent of workflow disruption, the measure, and availability of resources, risk perception, impact on working dynamics (e.g., workload, control, reward, community, fairness, values) and management (Leiter, 2020).

\section{Materials And Methods}

\section{Study population and participants}

The study population consisted of radiographers who work in Kuwait government, private hospitals, clinics, and newly authorized medical quarantine centers (Fig 1). The inclusion criteria consisted of all active radiographers of all ages, male or female, that have been and are still working in the locations mentioned earlier around January (the start of the pandemic) until the current time. Exclusion criteria include all other healthcare workers, radiography students, and radiographers who have not been active during the pandemic period. The survey was active online for participation from May 2020, until June 2020. The participants work in different areas within the department, such as general and portable X-ray, computed 
tomography (CT), magnetic resonance imaging (MRI), and ultrasound (US). Participation was voluntary, and all personal information was anonymous. The survey distribution was done through different channels to encourage participation; examples include sending group e-mails, using radiography phone groups, using hospital social media channels, and contacting the head of radiography staff.

\section{Pandemic Experiences \& Perceptions Survey (PEPS)}

A license was purchased from Mind Garden Incorporation to administer the PEPS tool. The tool consists of 2 pages, 34 questions in total (Table 1), with an additional page that included demographic variables such as age, gender, work experience, job title, and educational attainment (Table 2). To complete the survey, it takes about 10 to $15 \mathrm{~min}$. The PEPS uses five main tools: disruption (e.g., the extent of workflow disruption), resources (e.g., adequacy of resources to meet demands), risk perception (e.g., contact, control, potential harm), impact on work-life areas (e.g., workload, control, reward, community, fairness), and finally, perceptions of leadership (immediate and manager). The survey also included two open-text items identifying what would help employees and what gives them hope. 
Table 1: Categorization of PEPS tool, items and scales

\begin{tabular}{|c|c|c|c|}
\hline $\begin{array}{c}\text { Tool } \\
\text { number }\end{array}$ & PEPS tool name & $\begin{array}{c}\text { Number of items } \\
\text { included }\end{array}$ & Scale used \\
\hline 1 & Disruption & 3 & $\begin{array}{l}0=\text { No Effect at All } \\
1=\text { Small Effect } \\
2=\text { Moderate Effect } \\
3=\text { Large Effect } \\
4=\text { Completely Dominated the } \\
\text { Work }\end{array}$ \\
\hline 2 & Resources & 5 & $\begin{array}{l}0=\text { Completely Inadequate } \\
1=\text { Barely Adequate } \\
2=\text { Somewhat Adequate } \\
3=\text { Mostly Adequate } \\
4=\text { Completely Adequate }\end{array}$ \\
\hline 3 & Risk Perception & 4 & $\begin{array}{l}1=\text { No Risk at All } \\
2=\text { Minor Risk } \\
3=\text { Serious Risk } \\
4=\text { Life Threatening Risk }\end{array}$ \\
\hline 4 & $\begin{array}{c}\text { Impact on work-life } \\
\text { areas }\end{array}$ & 7 & $\begin{array}{l}1=\text { Strongly Disagree } \\
2=\text { Disagree } \\
3=\text { Hard to Decide } \\
4=\text { Agree } \\
5=\text { Strongly Agree }\end{array}$ \\
\hline 5 & Leadership & 10 & $\begin{array}{l}1=\text { Not at All } \\
2=\text { Once in Awhile } \\
3=\text { Sometimes } \\
4=\text { Fairly Often } \\
5=\text { Frequently, if not Always }\end{array}$ \\
\hline
\end{tabular}

\section{Data Analysis}

Data were analyzed using Wizard (version 1.9. 42), Excel \& Xlstat (version 16. 37), and Minitab Express (version 1.5.3) for mac. Descriptive analysis was reported as a percentage, and mean scores, average scoring, mean and standard deviation (SD) for all five PEPS tools obtained. T-test and ANOVA to analyze the relationship between the dependent (PEPS tools) and independent variables (demographic 
characteristics of the participants). All the differences of estimated variables were statistically significant if $\mathrm{P}<0.05$.

\section{Results}

The number of participants that have attempted to complete the survey was 347; however, only 102 participants completed the survey, $48(47.1 \%)$ males and 54 (52.9\%) females, the questionnaire had a mean $( \pm S D)$ age of $(35.7 \pm 8.2)$ years. $89 \%$ of participants have indicated that they have been in direct contact with COVID-19. Out of these participants, $57.8 \%$ have expressed that they roughly have had training, support, and equipment to provide them with some control over the virus. Furthermore, more than half of the participants (68.7\%) have expressed fear of the virus and that it presented a danger to them.

Participants were also asked two open-text questions, first to express what provided them with hope; $87 \%$ of the answers included one or a combination of the following items, management, family, friend, and religion, while $13 \%$ replayed with nothing. The second open-text question was on aspects of the working environment that participants felt should be improved; $66 \%$ of answers revolved around improving protective measures, equipment, management, and staff regulations, whereas $34 \%$ answered with nothing.

With regards to the five PEPS tools, the mean $( \pm$ SD) score scales were (table 1): Disruption $2.487( \pm 1.094)$, resources $2.580( \pm 1.196)$, risk perception $2.963( \pm 1.713)$, impact on work-life areas $3.810( \pm 0.992)$, and Leadership 3.795 ( \pm 0.965$)$. Radiographers who answered PEPS tool 1 thought that COVID-19 had a substantial effect on their work as an organization, $48 \%$, Unit $45.1 \%$, and personally $41.2 \%$ (fig 2 ). According to Table 2, where the association of demographic characteristics and PEPS for radiographers seen nationality was significantly affected by the changes $\mathrm{P}<0.001$. In the second PEPS tool, radiographers provided mixed opinions with regards to the tool items. Almost half of the radiographers agreed that management provided entirely adequate information (48\%); however, responses were mixed in rating staff support, availability, and equipment (fig 3). PEPS tool 3 shows radiographers agree that COVID19 presented serious risks (fig 4). Almost half of the radiographers believe that work-life impact was manageable and to their extent of experience and knowledge (fig 5). Half of the radiographers have a positive outlook on leadership, whether it be management or immediate supervisors in dealing with pandemic related issues (fig 6). 
Table 2: Characteristics of the respondents numbers,, percentage, and the distribution of PEPS five tools scores among healthcare workers (No. =102), statistic applied here was implemented according to (Zhang et al., 2020) study and has been adapted to this work.

Demographic $\quad$ No. $\quad \% \quad$ PEPS tool $1 \quad$ PEPS tool $2 \quad$ PEPS tool $3 \quad$ PEPS tool $4 \quad$ PEPS tool 5 variables

Disruption Resources $\quad$ Risk Impact on Leadership

Perception work-life areas

\begin{tabular}{|c|c|c|c|c|c|c|c|}
\hline Gender & & & ${ }^{*} P 0.121$ & ${ }^{*} P 0.013$ & $* P 0.141$ & $* P 0.002$ & $* P<0.001$ \\
\hline Male & 48 & 47.1 & $2.33( \pm 0.281)$ & $2.816( \pm 0.263)$ & $2.72( \pm 0.483)$ & $4.044( \pm 0.198)$ & $4.0854( \pm 0.192)$ \\
\hline Female & 54 & 52.9 & $2.62( \pm 0.247)$ & $2.37( \pm 0.241)$ & $3.176( \pm 0.384)$ & $3.600( \pm 0.188)$ & $3.537( \pm 0.229)$ \\
\hline Age & & & $* * P 0.273$ & $* * P 0.493$ & $* * P 0.890$ & **P 0.395 & $* * P 0.746$ \\
\hline $20-29$ & 27 & 26.4 & $2.49( \pm 0.456)$ & $2.4( \pm 0.432)$ & $2.88( \pm 0.483)$ & $4.044( \pm 0.640)$ & $3.744( \pm 0.305)$ \\
\hline $30-39$ & 45 & 44.1 & $2.34( \pm 0.279)$ & $2.63( \pm 0.259)$ & $3.176( \pm 0.384)$ & $2.933( \pm 0.459)$ & $3.864( \pm 0.214)$ \\
\hline$>40$ & 30 & 29.4 & $2.66( \pm 0.266)$ & $2.66( \pm 0.263)$ & $2.72( \pm 0.308)$ & $3.075( \pm 0.576)$ & $3.736( \pm 0.362)$ \\
\hline Nationality & & & $* P<0.001$ & $* P 0.053$ & $* P 0.009$ & $* P 0.001$ & $* P<0.001$ \\
\hline Kuwaiti & 46 & 45.1 & $2.86( \pm 0.233)$ & $2.387( \pm 0.251)$ & $3.402( \pm 0.405)$ & $3.481( \pm 0.201)$ & $3.421( \pm 0.248)$ \\
\hline Non-Kuwaiti & 54 & 54.9 & $2.17( \pm 0.256)$ & $2.739( \pm 0.254)$ & $2.602( \pm 0.428)$ & $4.079( \pm 0.171)$ & $4.101( \pm 0.171)$ \\
\hline Radiographers level & & & **P 0.102 & **P 0.587 & $* * P 0.004$ & **P 0.017 & **P 0.001 \\
\hline Junior & 11 & 10.8 & $2.606( \pm 0.283)$ & $2.254( \pm 0.345)$ & $3.41( \pm 0.499)$ & $3.44( \pm 0.246)$ & $3.35( \pm 0.249)$ \\
\hline practitioner & & & & & & & \\
\hline Practitioner & 35 & 34.3 & $2.133( \pm 0.187)$ & $2.77( \pm 0.179)$ & $2.16( \pm 0.241)$ & $4.14( \pm 0.116)$ & $4.16( \pm 0.094)$ \\
\hline Senior & 17 & 16.7 & $2.490( \pm 0.200)$ & $2.40( \pm 0.187)$ & $2.88( \pm 0.397)$ & $3.91( \pm 0.152)$ & $3.84( \pm 0.222)$ \\
\hline
\end{tabular}


practitioner

Specialist $\quad 15 \quad 14.7 \quad 2.55( \pm 0.204) \quad 2.62( \pm 0.232) \quad 3.63( \pm 0.329) \quad 3.55( \pm 0.161) \quad 3.65( \pm 0.181)$

$\begin{array}{llllllll}\text { Senior } & 11 & 10.8 & 2.757( \pm 0.180) & 2.381( \pm 0.232) & 3.27( \pm 0.326) & 3.56( \pm 0.210) & 3.82( \pm 0.242)\end{array}$

specialist

Chief $\quad 8 \quad 7.8 \quad 2.958( \pm 0.323) \quad 2.825( \pm 0.326) \quad 3.88( \pm 0.524) \quad 3.54( \pm 0.298) \quad 3.28( \pm 0.388)$

specials

$\begin{array}{llllllll}\text { Other } & 5 & 4.9 & 2.133( \pm 0.169) & 2.48( \pm 0.332) & 3.75( \pm 0.661) & 3.74( \pm 0.139) & 3.32( \pm 0.364)\end{array}$

Work Experience $\quad{ }^{* * P} 0.060 \quad{ }^{* * P} 0.083 \quad{ }^{* * P} 0.044 \quad * * P 0.012 \quad{ }^{* * P} 0.008$

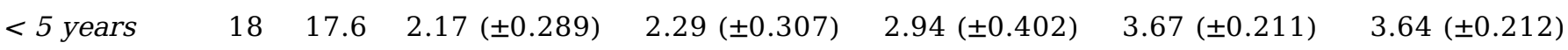

$5-10$ years $\quad 43 \quad 30.4 \quad 2.38( \pm 0.152) \quad 2.80( \pm 0.127) \quad 2.56( \pm 0.221) \quad 4.05( \pm 0.091) \quad 4.08( \pm 0.078)$

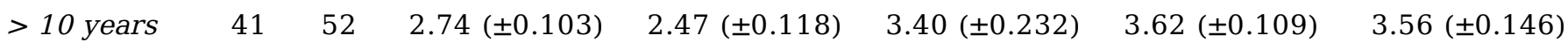

Education level $\quad * * P 0.047 \quad * * P 0.155 \quad * * P 0.041 \quad * * P 0.191 \quad * * P 0.146$

$\begin{array}{llllllll}\text { Associate } & 5 & 5 & 2.60( \pm 0.245) & 1.88( \pm 0.372) & 3.40( \pm 1.111) & 3.80( \pm 0.305) & 0.16( \pm 3.438)\end{array}$

degree

(diploma)

$\begin{array}{llllllll}\text { College } & 73 & 71.5 & 2.35( \pm 0.118) & 2.66( \pm 0.110) & 2.72( \pm 0.172) & 3.89( \pm 0.085) & 0.09( \pm 3.701)\end{array}$

(bachelor)

Postgraduate $24 \quad 23.5 \quad 2.89( \pm 0.137) \quad 2.48( \pm 0.169) \quad 3.60( \pm 0.287) \quad 3.58( \pm 0.140) \quad 0.19( \pm 3.125)$

(e.g. Master

( $P h D$ ) 
Yes

NO
16

15.6

$2.44( \pm 0.103)$

$2.61( \pm 0.104)$

$2.83( \pm 0.167)$

$3.83( \pm 0.079)$

$0.09( \pm 3.671)$

$0.22( \pm 3.083)$

Data were expressed as mean $( \pm S E), t$-test and ANOVA were test used to a comparison between demographic characteristics of Radiographers and the score of the five PEPS tools, ${ }^{*} P<0.05 .{ }^{* *} P<0.005$.

\section{Discussion}

COVID-19 is a recent phenomenon globally manifested compelling healthcare workers to face and rapidly adapt to forceful changes. Pandemics' impact is often intense; reports that provide radiographers feedback about their work experience can be an excellent source for required pandemic data. Moreover, Kuwait's radiographic population is a diverse environment; it consists of a wide range of ethnicities, varying genders, and physical abilities; thus, the generated results from this report could be of great help to other healthcare workers in formulating recovery plans and for future preparedness.

This study is the first conducted in Kuwait that measure pandemic experiences and perceptions for radiographers to the best of our knowledge. This study started in the early to middle stages of the COVID19 outbreak in areas that were non-pandemic but critically affected, and during a full lockdown of the country. First, the extent of the work-flow disruption for radiographers measures, $80 \%$ of radiographers agreed that COVID-19 affects their work as an organization, unit, and on them. When dealing with an epidemic, forced changes must be applied to overcome several factors (e.g., spread/infection). Recent publications suggest some of the most effective ways to control the spread of the virus are by changing the dynamics of the working environment like segregating radiographers into teams, reducing the number of working staff (e.g., secretaries, administrators), continuously having to disinfect equipment, using additional isolation rooms, and increasing the use of mobile radiography units (Food and Drug Administration Staff, 2020, (Kooraki, Hosseiny, Myers and Gholamrezanezhad, 2020, (Stogiannos, Fotopoulos, Woznitza and Malamateniou, 2020). Also, having to daily wear heavy protective gear such as gloves, head cap, disposable gown, shoe covers, and protective goggles can be exhausting and timeconsuming (Occupational Safety and Health Administration (OSHA), 2020, Kooraki, Hosseiny, Myers and Gholamrezanezhad, 2020, Mohakud, Ranjan, Naik and Deep, 2020). Consequently, radiographers rated these precautions in the second PEPS tool. In this section, management, resources, and control scores show, $4.9 \%$ found that management's information was completely inadequate, and $47.1 \%$ felt that they had some form of adequate information, while $48 \%$ agree to complete adequate information from their management in dealing with this crises. Conversely, most radiographers $(74.5 \%)$ agreed that their protective equipment, staff availability, and support staff competence were not adequate. Consequently, this would affect their risk perception, which is the third Item in the PEP survey. Participants scored risk perception (e.g., contact, virulence, and control), underestimating risk can prompt unnecessary incidents (e.g., carelessness, negligence); lack of awareness often leads to an unconcerned attitude, which may 
adversely affect the preparedness to meet these challenges, also, overestimating risk can undermine organizational effectiveness (e.g., panic, chaos, fear). $62 \%$ of the participants reported that they feared the virus and felt underprepared in dealing with it, and they scored $54 \%$ risk perception of their colleges. However, less than half of the participants believe that the virus would not be of great risk to the public (45\%) or their families (49\%). Significant demographics that affect this tool include participants nationalities $(P 0.009<0.05)$, health condition $(P 0.050<0.05)$ and radiographic working level $(P 0.004$ $<0.005)$. Moreover, more than half of the participating radiographers in this study had more than ten years of working experience (52\%), and an education level of bachelor (71.5\%) or higher $(23.5 \%)$ (Table 2 ). However, these factors, surprisingly, showed no significance in any PEPS tools. Radiography is a skillbased practice where it requires a certain amount of knowledge; however, it also needs continuous forms of ongoing education, and updates (Elshami, Elamrdi, Alyafie and Abuzaid, 2016). Like most healthcare workers, radiographers have to be familiar with frequent job training, specifically during a pandemic; ongoing training provides new, critical information regardless of previous knowledge (Kooraki, Hosseiny, Myers and Gholamrezanezhad, 2020). having training and knowledge enables workers to feel confident to do their work, thus providing some measure of stress reduction (Bhagavathula et al., 2020). All epidemics and pandemics have their unique characteristics in terms of causality, progression, and control measures (Roy et al., 2020). It is crucial to provide health education and create awareness during such situations to effectively prevent disease spread (Johnson and Hariharan, 2017). Also, in a previous study, health professionals often have better awareness, positive attitudes towards epidemics/pandemics, and often experience low anxiety (Mishra et al., 2016). Nevertheless, studies from Ethiopia reported poor knowledge and erroneous healthcare professionals' beliefs during the two outbreak in 2015, and 2020, both studies urged for intense training of the healthcare professionals (Abebe et al., 2016, Jemal et al., 2020). In a study conducted in Trinidad and Tobago in 2016, following the H1N1 epidemic, it was seen that a significant proportion of the general public was unaware of the seriousness and measures of prevention of the epidemic (Johnson and Hariharan, 2017). Research suggests that although radiographers perform a similar technical occupation, the impact of the country culture on radiography manifests through the scope of practice and level of recognition within the healthcare spectrum (Cowling and Lawson, 2020). This study showed radiographers performing a similar technical occupation; however, the departments were in a wide variety of cultural and socio-economic environments, which significantly affected the radiographer. Finally, the work-life and leadership sections (PEPS 4 - 5) identify management areas that employees perceive as going well and where they would appreciate the improvement. More than $70 \%$ agreed to flexible working hours, workload being within their capabilities, felt supported, had a good sense of community, fairness, and no conflict between priorities and values. Similarly, almost half of the participants agree that leadership, whether it be management or immediate supervisors, provided hope, confidence, honest assessment, and a safe environment. It is the manager's and supervisors' responsibility to provide training about the outbreak in a formal setting to ensure that all workers understand details about disease transmission, screening, use of personal protection equipment. Radiographer's working-level showed significance in reporting PEPS tool five, which is understanding that the radiographer level indicates work responsibilities and supervision duties as their level increases obligations and responsibilities increase. The majority of radiographers explained fear and risk of working with COVID-19; however, they had a positive attitude toward their leadership and management. Most radiographers explained that regardless of their 
faith in management, additional education interventions and campaigns were required to improve their sense of safety and confidence. Working with an insensitive working environment of COVID-19, any organization will experience some burnout, depending on both the quality of the management system and how leaders react in real-time. This PEPS tool can help to contain future burnouts and conflicts.

\section{Limitations}

Despite the findings introduced here, It is important to stress that this survey showed some limitations; the number of radiographers and participation was deficient; it was challenging to urge people to complete the survey regardless of all the rigorous methods of engorgements. Also, another factor could be the short period of data collection that could have led to that. Nevertheless, this is considered a moderate sample size. Moreover, this pandemic caused many to be busy watching the news and taking care of personal affairs. Thus, participation revolved around radiographers who were active on the internet or social media during the short period of data collection, which might have led to selection bias and sampling error, which prevents the ability to generalize our results.

\section{Conclusion}

Medical practice differs widely among different countries, mainly due to the variability of access to resources (e.g., viral testing and imaging equipment, specialized staff, protective equipment). Medical Imaging plays an essential auxiliary role in diagnosing COVID-19 patients; it has been well-documented that chest radiographs should be the first-line imaging tool for diagnosing and monitoring COVID-19 patients (Fotopoulos, Woznitza and Malamateniou, 2020). Radiology departments must re-organize their facilities and staff to enhance safety and minimize the risks of infection (Sim et al., 2020). Supporting radiographers' health and emotional well-being is key to maintaining essential services, now more than ever, as the daunting COVID-19 outbreak stresses workers.

\section{Declarations}

\section{Ethics}

The study maintained confidentiality by making all participants' information anonymous throughout the study. Eligible Radiographers' participation in this survey was entirely voluntary. Before undertaking the survey, all participants signed electronic informed consent to activate the survey. Also, for every survey link sent by e-mail, there was a consent included. The study followed the Declaration of Helsinki checklist for reporting results of internet e-surveys (CHERRIES) guidelines, which includes having to take ethical clearance and approval from Kuwait's ministry of health ethical review board.

\section{Conflict of interest statement}

The author declare that there is no conflict of interest.

\section{References}


1. Abebe, T., Bhagavathula, A., Tefera, Y., Ahmad, A., Khan, M., Belachew, S., Brown, B. and Abegaz, T., 2016. Healthcare professionals' awareness, knowledge, attitudes, perceptions and beliefs about Ebola at Gondar University Hospital, Northwest Ethiopia: a cross-sectional study. Journal of Public Health in Africa, 7(2).

2. Addinsoft (2020). XLSTAT statistical and data analysis solution. New York, USA. Https://www.xlstat.com.

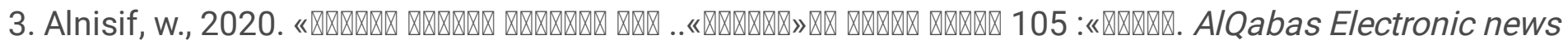

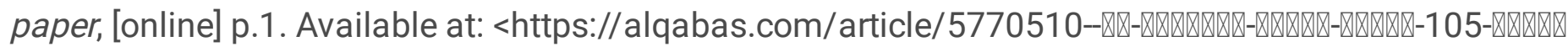
Q

4. Bhagavathula, A., Aldhaleei, W., Rahmani, J., Mahabadi, M. and Bandari, D., 2020. Knowledge and Perceptions of COVID-19 Among Health Care Workers: Cross-Sectional Study. JMIR Public Health and Surveillance, 6(2), p.e19160.

5. Catton, H., 2020. ICN Calls For Data On Healthcare Worker Infection Rates And Deaths. [online] ICN International Council of Nurses. Available at: <https://www.icn.ch/news/icn-calls-data-healthcareworker-infection-rates-and-deaths> [Accessed 14 July 2020].

6. Chersich, M., Gray, G., Fairlie, L., Eichbaum, Q., Mayhew, S., Allwood, B., English, R., Scorgie, F., Luchters, S., Simpson, G., Haghighi, M., Pham, M. and Rees, H., 2020. COVID-19 in Africa: care and protection for frontline healthcare workers. Globalization and Health, 16(1).

7. Cowling, C. and Lawson, C., 2020. Assessing the impact of country culture on the socio-cultural practice of radiography. Radiography,

8. Elshami, W., Elamrdi, A., Alyafie, S. and Abuzaid, M., 2016. Continuing professional development in radiography: practice, attitude and barriers. International Journal of Medical Research \& Health Sciences, 5(1), p.68.

9. Flor, N., Dore, R. and Sardanelli, F., 2020. On the Role of Chest Radiography and CT in the Coronavirus Disease (COVID-19) Pandemic. American Journal of Roentgenology, pp.W1-W1.

10. Food and Drug Administration Staff, 2020. Enforcement Policy For Imaging Systems During The Coronavirus Disease 2019 (COVID-19) Public Health Emergency. Guidance for Industry and Food and Drug Administration Staff. [online] Rockville: U.S. Department of Health and Human Services Food and Drug Administration Center for Devices and Radiological Health (CDRH) Office of Product Evaluation and Quality (OPEQ), pp.1-19. Available at: <https://www.fda.gov/media/137290/download> [Accessed 14 July 2020].

11. Jemal, B., Ferede, Z., Mola, S., Hailu, S., Abiy, S., Wolde, G., Tilahun, A., Tesfaye, B., Lemma, D., Alimaw, A., Neme, D., Regasa, T., Mulugeta, H., Moges, K. and Bedru, M., 2020. Knowledge, attitude and practice of healthcare workers towards COVID-19 and its prevention in Ethiopia: a multicenter study. research square, 1.

12. Johnson, E. and Hariharan, S., 2017. Public health awareness: knowledge, attitude and behaviour of the general public on health risks during the H1N1 influenza pandemic. Journal of Public Health, 25(3), pp.333-337. 
13. Kooraki, S., Hosseiny, M., Myers, L. and Gholamrezanezhad, A., 2020. Coronavirus (COVID-19) Outbreak: What the Department of Radiology Should Know. Journal of the American College of Radiology, 17(4), pp.447-451.

14. Leiter, M., 2020. The Pandemic Experiences And Perceptions Survey (PEPS). Group report. Mind garden inc, pp.1-57.

15. Mishra, P., Bhadauria, U., Dasar, P., Kumar, S., Lalani, A., Sarkar, P., Chauhan, A., Godha, S. and Vyas, S., 2016. Knowledge, attitude and anxiety towards pandemic flu: a potential bio weapon among health professionals in Indore city. Epidemiol, 70(1), pp.41-5.

16. Mohakud, S., Ranjan, A., Naik, S. and Deep, N., 2020. COVID-19 preparedness for portable x-rays in an Indian hospital - Safety of the radiographers, the frontline warriors. Radiography, 26(3), pp.270-271.

17. Occupational Safety and Health Administration (OSHA), 2020. Guidance On Preparing Workplaces For COVID-19. U.S. Department of Labor. [online] U.S. Department of Labor, pp.1-35. Available at: <https://www.osha.gov/Publications/OSHA3990.pdf> [Accessed 14 July 2020].

18. Roy, D., Tripathy, S., Kar, S., Sharma, N., Verma, S. and Kaushal, V., 2020. Study of knowledge, attitude, anxiety \& perceived mental healthcare need in Indian population during COVID-19 pandemic. Asian Journal of Psychiatry, 51, p.102083.

19. Sim, W., Chen, R., Aw, L., Abu Bakar, R., Tan, C., Heng, A. and Ooi, C., 2020. How to safely and sustainably reorganise a large general radiography service facing the COVID-19 pandemic. Radiography,.

20. Stevens, B., 2020. Reporting radiographers' interpretation and use of the British Society of Thoracic Imaging's coding system when reporting COVID-19 chest x-rays. Radiography,

21. Stogiannos, N., Fotopoulos, D., Woznitza, N. and Malamateniou, C., 2020. COVID-19 in the radiology department: What radiographers need to know. Radiography, 26(3), pp.254-263.

22. Yurdaisik, I. and Nurili, F., 2020. Evaluation of Chest CT Findings in 50 Coronavirus Disease 2019 (COVID-19) Patients Treated in Turkey. Cureus,.

23. Zhang, M., Zhou, M., Tang, F., Wang, Y., Nie, H., Zhang, L. and You, G., 2020. Knowledge, attitude, and practice regarding COVID-19 among healthcare workers in Henan, China. Journal of Hospital Infection, 105(2), pp.183-187.

\section{Figures}




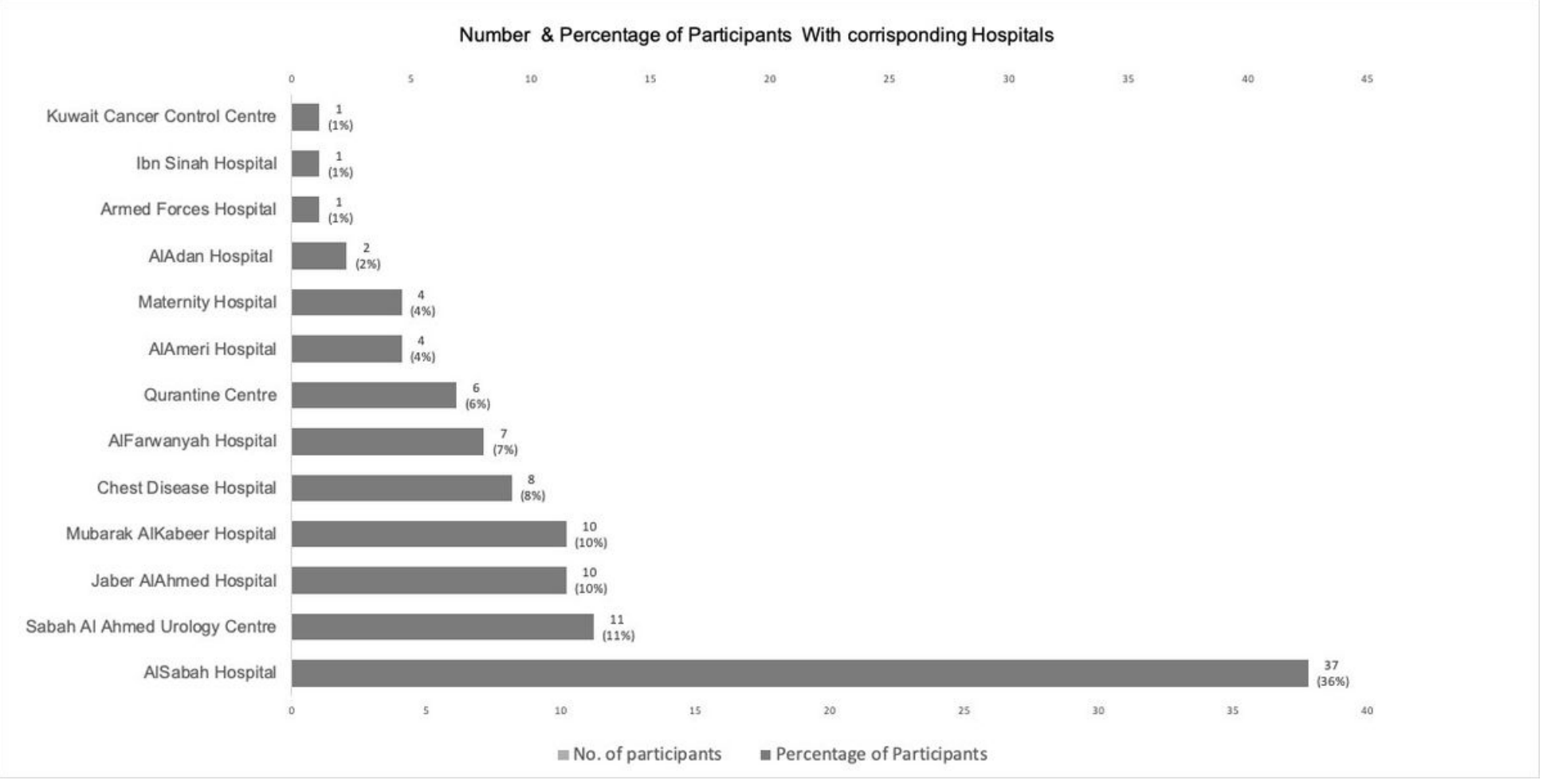

Figure 1

Distribution of the study participants and their corresponding hospitals in Kuwait

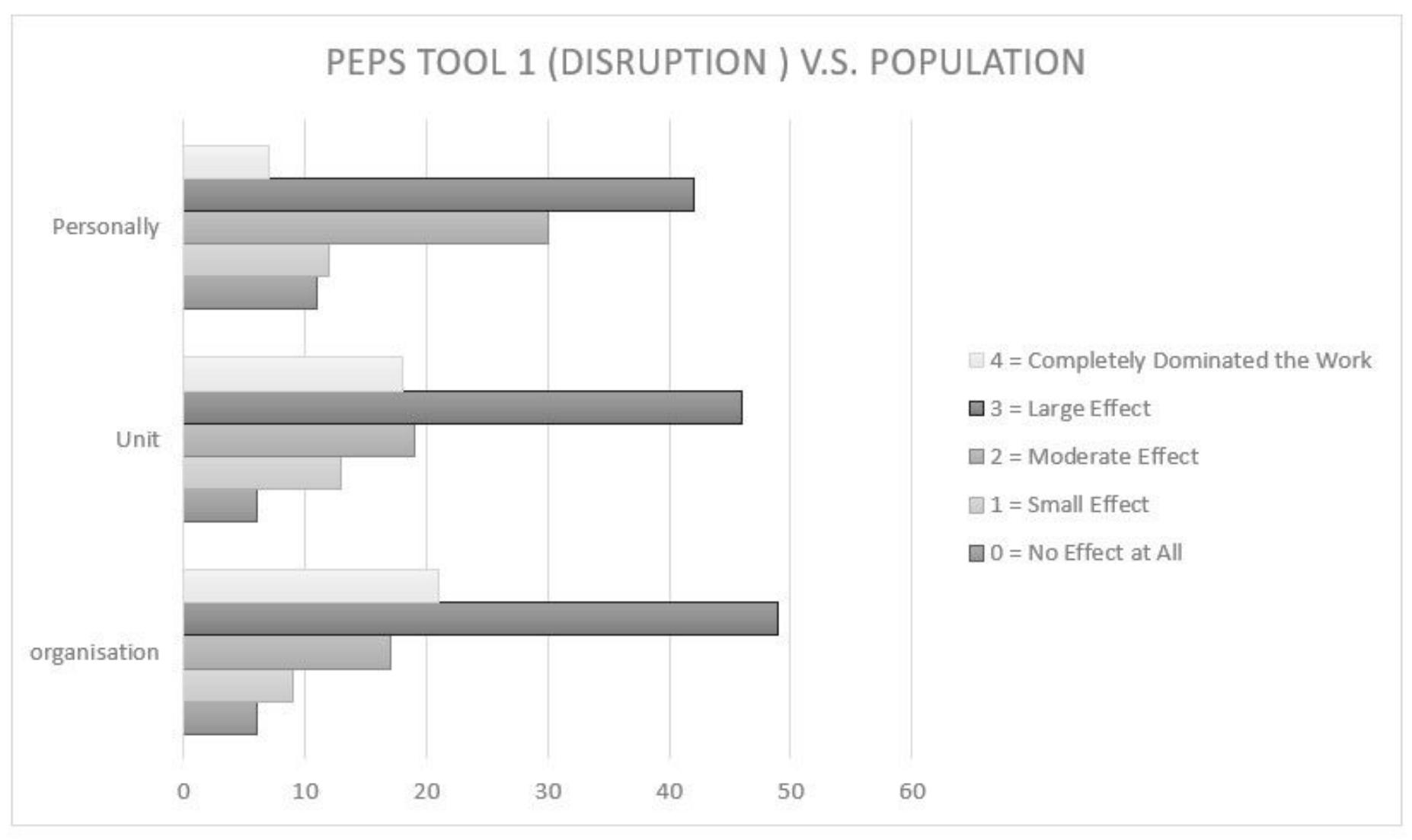

Figure 2 
Bar chart showing score of PEPS tool 1 and radiographers feedback to each tool item

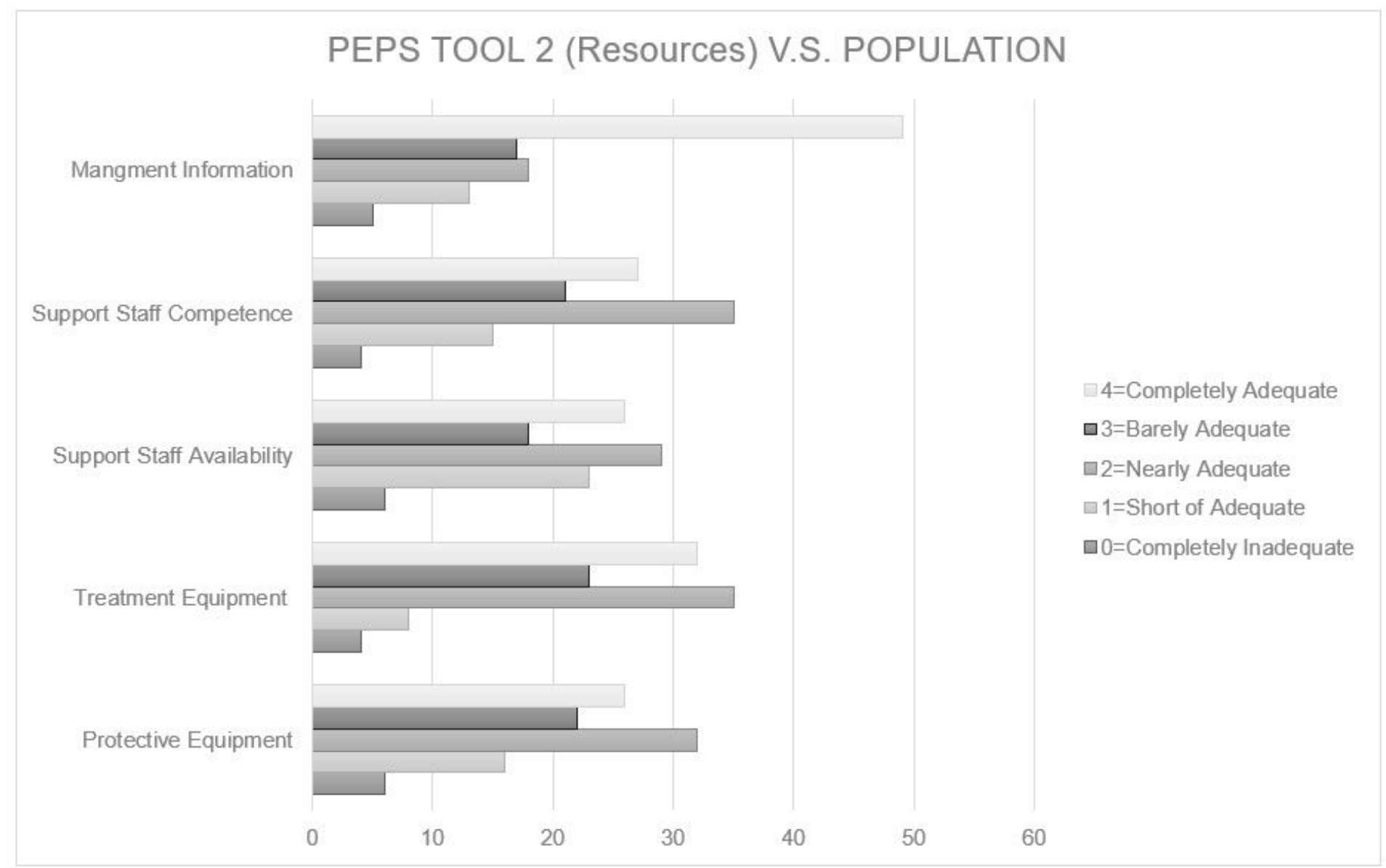

\section{Figure 3}

Bar chart showing score of PEPS tool 2 and radiographers feedback to each tool item 


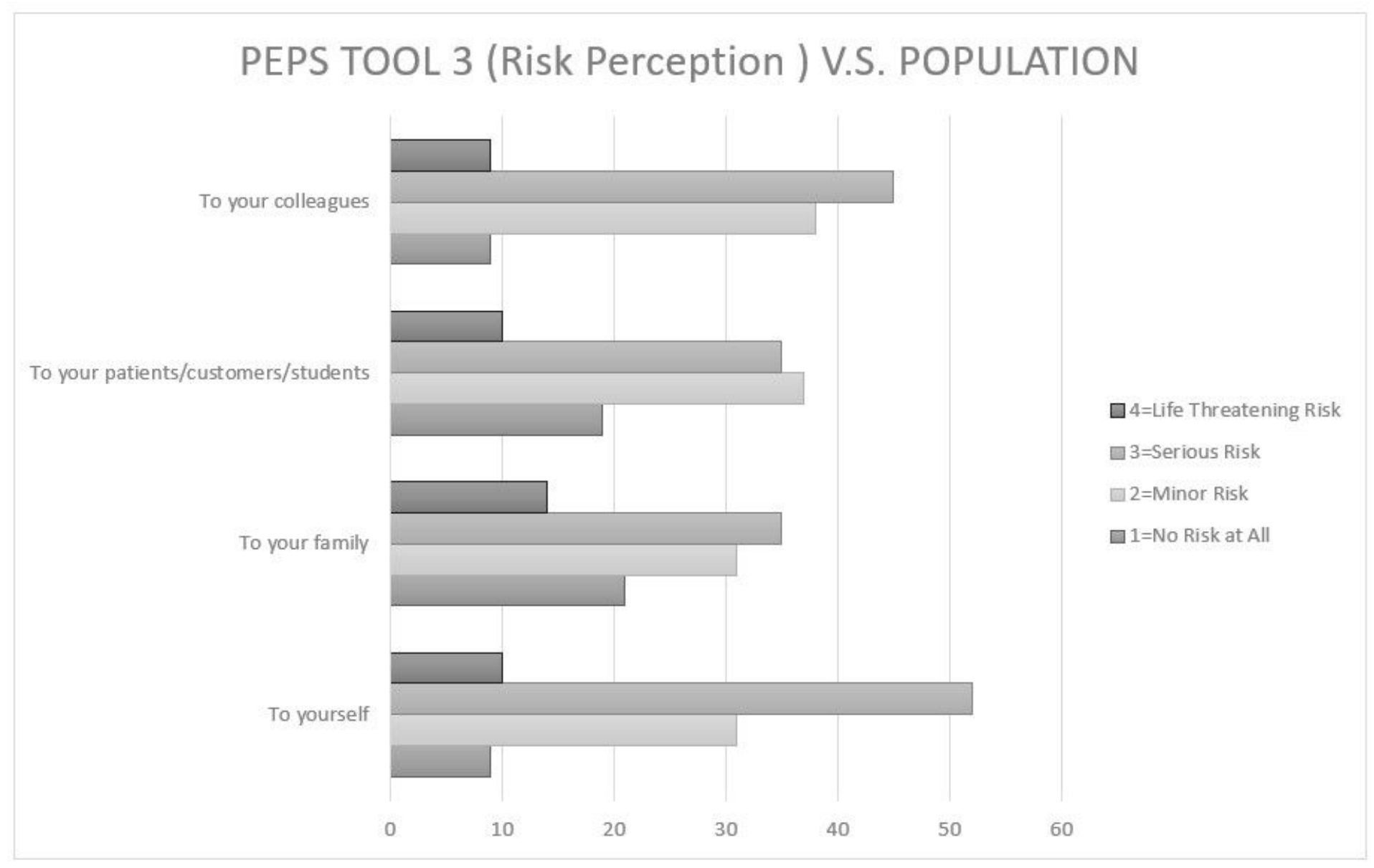

Figure 4

Bar chart showing score of PEPS tool 3 and radiographers feedback to each tool item 


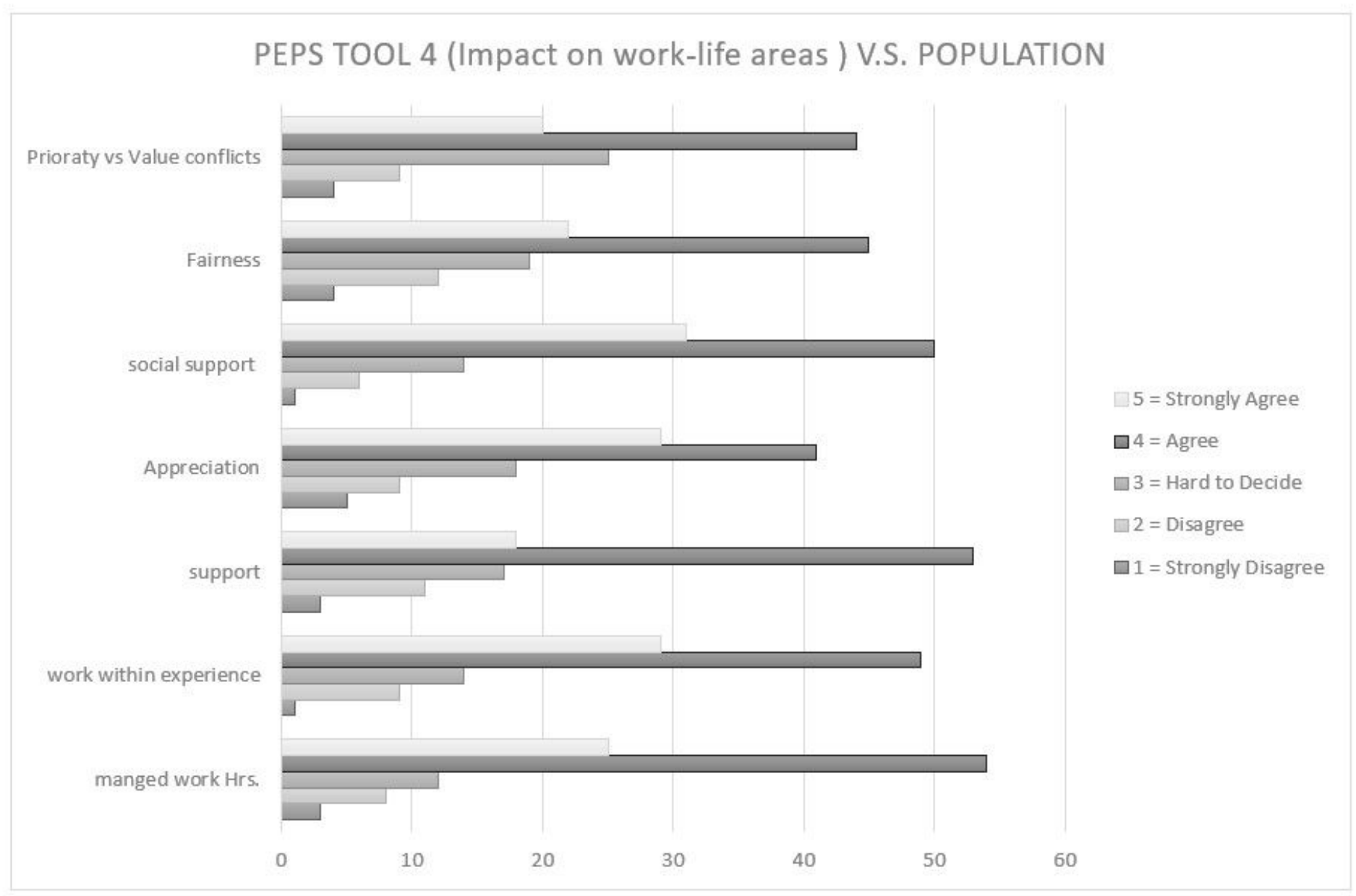

\section{Figure 5}

bar chart showing score of PEPS tool 4 and radiographers feedback to each tool item 


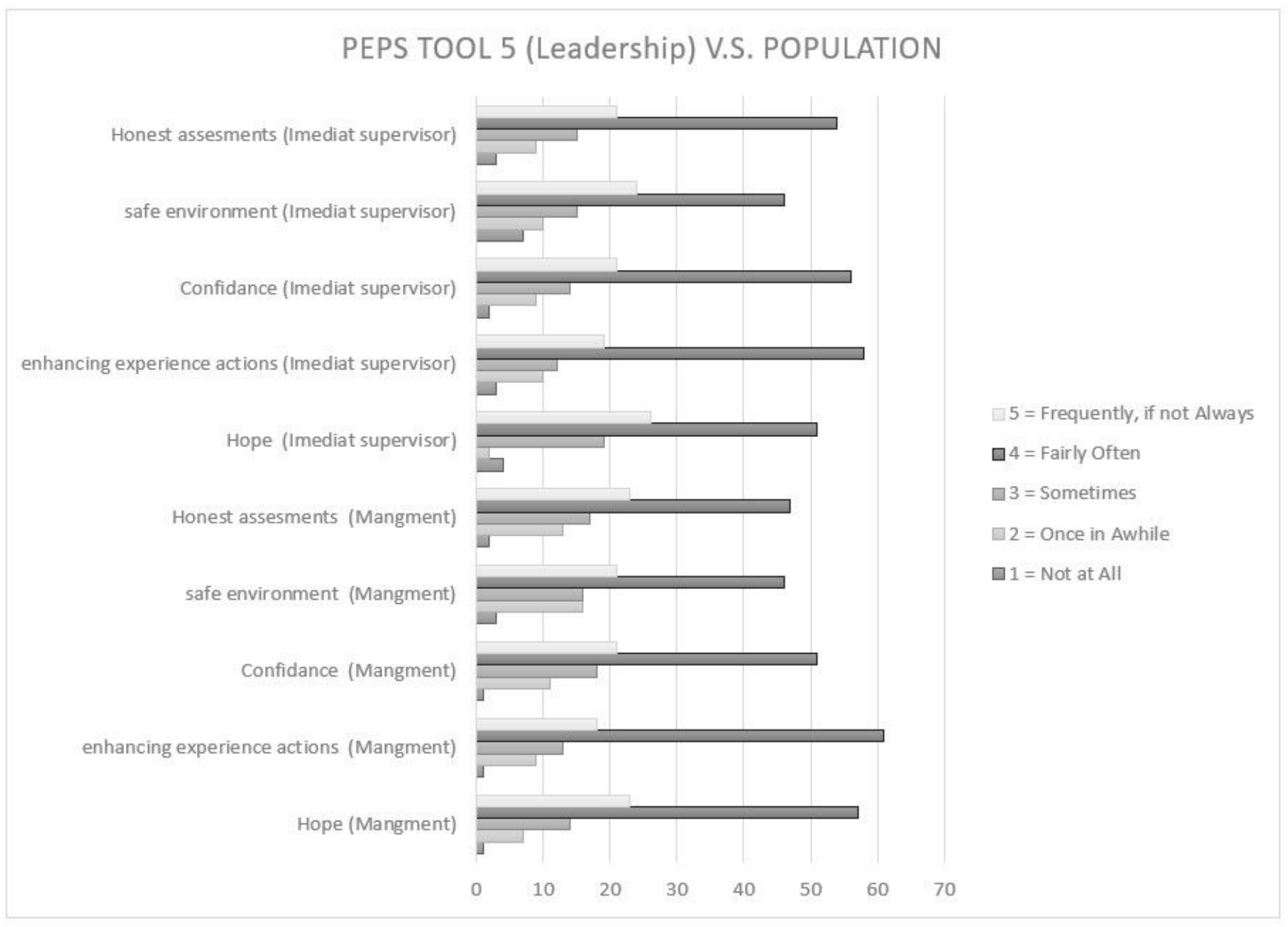

\section{Figure 6}

Bar chart showing score of PEPS tool 5 and radiographers feedback to each tool item 